\title{
The Epistemology of Prejudice
}

\author{
Endre Begby \\ Simon Fraser University \\ endre.begby@gmail.com
}

\begin{abstract}
According to a common view, prejudice always involves some form of epistemic culpability, i.e., a failure to respond to evidence in the appropriate way. I argue that the common view wrongfully assumes that prejudices always involve universal generalizations. After motivating the more plausible thesis that prejudices typically involve a species of generic judgment, I show that standard examples provide no grounds for positing a strong connection between prejudice and epistemic culpability. More generally, the common view fails to recognize the extent to which prejudices are epistemically insidious: once they are internalized as background beliefs, they quite reasonably come to control the assessment and interpretation of new evidence. This property of insidiousness helps explain why prejudices are so recalcitrant to empirical counterevidence and also why they are frequently invisible to introspective reflection.
\end{abstract}

1. A prejudice, let us say, is a negatively charged, materially false, stereotype targeting some social group and, derivatively, the individuals that comprise this group. But to classify prejudices as false is not yet to say much about their epistemology: after all, many of our false beliefs appear to be in good evidential standing. Nonetheless, a common view appears to hold that prejudices always arise from some specifiable mishandling of evidence, in such a way that we can say that those who harbor prejudices are "epistemically culpable" (Fricker 2007) or are displaying a distinctive kind of "epistemic irrationality" (Arpaly 2003). Accordingly, there may be a complex psychological story to be told about why and how people maintain prejudices even in the face of contradictory evidence, a story that might make reference to mechanisms of 
(implicit) bias, motivated believing, and so on. From an epistemological point of view, by contrast, prejudice seems a comparatively simple affair. ${ }^{1}$

This paper aims to put this common view to the question. My argument pivots on a reexamination of what one might call the logical structure of prejudice. When the common view posits a strong connection between prejudice and epistemic culpability, it takes for granted a characterization of prejudices in terms of universal generalizations (i.e., prejudices ascribe a particular property to each member of some group). But this characterization does not appear to be correct, at least for the majority of common and pernicious prejudices. Specifically, thinking of prejudices in terms of universal generalization would fail to draw the consequences of the fact that prejudices are, as noted above, stereotype judgments. As such, we should expect that their logical structure is closer in kind to generic judgments, such as "ducks lay eggs." For the purposes of this paper, the relevant point to observe is that generic judgments stand in a much more complex relationship to negative instances than do universal generalizations. ${ }^{2}$ I conclude that once the logical structure of prejudice is properly taken into account, it may no longer be clear from standard cases that an epistemic mistake has been made when a person maintains a prejudice in the face of contrary evidence. Instead, we must recognize that prejudices are epistemically insidious: once they are internalized as background beliefs, they quite reasonably come to control the assessment and interpretation of new evidence. This property of

\footnotetext{
${ }^{1}$ Having drawn this distinction, I should specify that my argument will be narrowly focused on the evidential question, assessing what sorts of belief adjustments we are or are not rationally required to make in light of certain kinds of evidence. I will not here attempt to address the important psychological question about the extent to which we are capable of making such adjustments, or how we should think about cases where stereotyping behavior persists even after the requisite belief adjustments have been made (e.g., cases of "implicit bias," much discussed in recent literature). For an overview of such issues, see Gendler 2011.

${ }^{2}$ See, for instance, Sarah-Jane Leslie 2008; forthcoming. As Leslie points out, a generic judgment such as "ducks lay eggs" is generally recognized as true, even though only female ducks do. By contrast, "ducks are female" is emphatically not true, even though it encounters fewer negative instances than does "ducks lay eggs."
} 
insidiousness helps explain why prejudices are so recalcitrant to empirical counterevidence and also why they are frequently invisible to introspective reflection.

2. Our guiding question, then, is whether prejudices always, or even typically, involve some specifiable kind of epistemic culpability or irrationality. I will approach the problem through the lens of an example first offered by Nomy Arpaly (2003) and subsequently taken up by Miranda Fricker (2007). The example concerns Solomon, "a boy who lives in a small, isolated farming community in a poor country," and who "believes that women are not half as competent as men when it comes to abstract thinking, or at least are not inclined toward such thinking" (Arpaly 2003: 103). Arpaly notes that Solomon's negative stereotype might have ample evidential support. For instance, he has direct empirical evidence gained from interacting with women in his community - none of whom has displayed any aptitude of the relevant sort -, as well as testimonial evidence from peers, much of which has presumably been filtered into his education, such as it is.

In light of the evidence available to him, Arpaly (2003: 104) and Fricker (2007: 33-34) agree that Solomon is not epistemically culpable for his false negative stereotype against women at this point. This situation is to be contrasted with a second step of the example, in which Solomon receives and accepts an entrance fellowship to a university. At the university, he regularly interacts with women who display a strong aptitude for abstract thinking. How should Solomon deal with this new evidence? Arpaly and Fricker again agree that if Solomon persists in believing that women are inferior to men in the realm of abstract thinking, then he is prejudiced. He is prejudiced because he has culpably failed to revise his negative opinion of women's 
intellectual capacities in light of contrary evidence. He was not prejudiced previously - in spite of holding the same stereotype - because he had no access to such evidence.

But what is the exact nature of Solomon's epistemic error at this point? When we try to specify the nature of his error, we quickly run into the question of how we should characterize the logical structure of Solomon's negative stereotype. The common view appears to implicitly cash out Solomon's prejudice in terms of a universally quantified generalization based on inductive evidence, akin, say, to "all ravens are black." His epistemic culpability would consist simply in failing to recognize intelligent women as counterexamples to that generalization. In essence, he neglects or discounts evidence for female intelligence, showing a bias in favor of evidence that women are less intelligent. There may be a complicated psychological story to be told about why he is so resistant to recognizing intelligent women as counterexamples to his stereotype. But from an epistemological point of view, there is no doubt that he should, and that he is culpable if he does not.

Such bias no doubt exists, and might well be operant in the case at hand. But this analysis fails to draw the consequences of the fact that prototypical prejudices, qua stereotype judgments, are not plausibly cashed out as universal generalizations at all: they do not say that all members of a group have a particular trait, or display a particular trait to the same extent. Instead, they say that it is typical of a group that it displays the trait to a greater extent than other groups. Consequently, it may be perfectly consistent with maintaining a false negative stereotype to allow that different members of the group in question will display the undesirable trait to different degrees, some maybe not at all. 
3. To see how, it will be helpful to take a closer look at Arpaly's characterization of the case. Arpaly (2003: 103) glosses Solomon's stereotype in terms of the belief that "women are not half as intelligent as men." This gloss leaves many details undetermined. One way of understanding this belief would be as expressing the universally quantified judgment that there is no woman who is half as intelligent as any man. But this would constitute an exceptionally naïve and not particularly representative stereotype. Indeed, it is doubtful that any cogent elaboration on Solomon's situation even prior to his entering the university could really have him believe such a thing. Presumably, for instance, Solomon recognizes that intelligence is not equally distributed within the male population. For a simple example, assume that Solomon has a Cousin Ron whom he regards as particularly obtuse. Ron, Solomon reflects, is probably every bit as dim as most women. Accordingly, it is perfectly within Solomon's capabilities to recognize that some men are as obtuse as some women. If so, we should also expect that he is capable of drawing the inference that not all women are equally obtuse; rather, some women are more intelligent than others.

Thus, to determine the exact nature of Solomon's prejudice, we need to move beyond Arpaly's quick gloss "women are not half as intelligent as men." Since Solomon is presumably able to recognize that there is significant variation in intelligence within each group, men and women, it is rather more plausible to attempt to express his prejudice in a judgment of the form, women are typically (or on average) less intelligent than men. For the sake of simplicity, let us assume that he believes intelligence displays some manner of normal distribution within each group. 
Fig. 1:

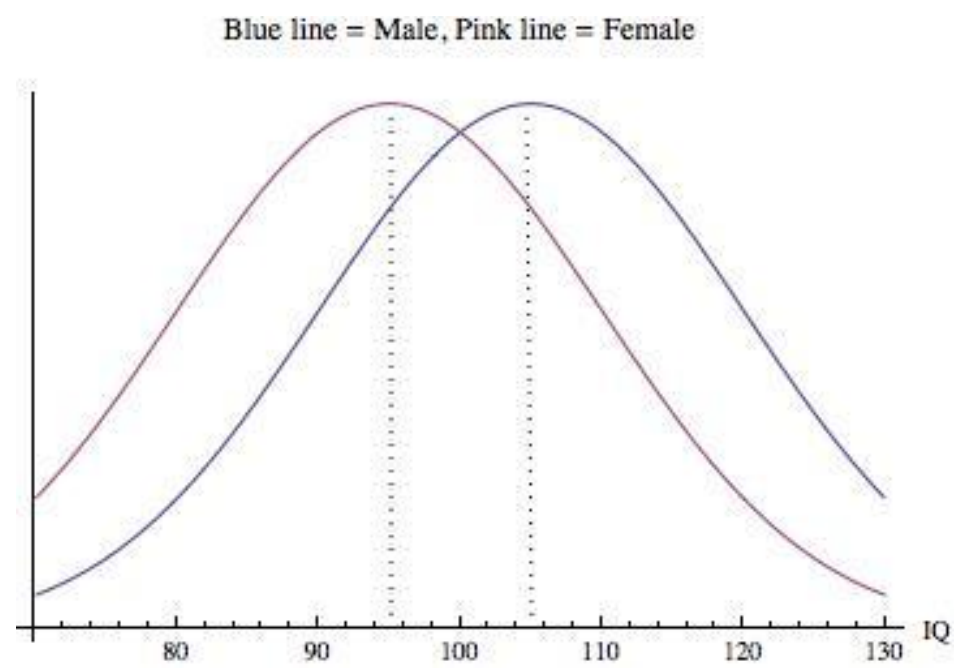

While this departs somewhat from the story of Solomon as presented by Arpaly and Fricker (most notably, perhaps, in substituting a generalized notion of "intelligence" for a capacity for "abstract thinking"), it is also, I contend, a more faithful representation of the sort of stereotype that women have to contend with today. ${ }^{3}$ Of course, Arpaly and Fricker might insist that Solomon takes an even dimmer view of female intelligence than the average male chauvinist does, in which case the values would have to be tweaked. But the point to note here is simply that, qua stereotype judgments, typical prejudices allow that a trait exhibits some manner of normal distribution within the targeted group. (Coarsely put, if Solomon would not allow this, we would not have to wait until he enters the university to charge him with epistemic culpability; he would already be guilty of neglecting clear evidence that even within the female population he has encountered so far, some individuals are smarter than others.)

\footnotetext{
${ }^{3}$ Indeed, the diagram is adopted from a popular website -- http://www.iqcomparisonsite.com/ -- which claims to tell the unvarnished scientific truth about the comparative intelligence of various population groups. (I should emphasize that I am in no way endorsing the content of the graph, but precisely using it to illustrate what I take to be a representative instance of prejudiced belief.)
} 
4. With this in mind, let us turn to assess the evidence that Solomon acquires when he enters the university and encounters highly intelligent women for the first time. This would, of course, constitute decisive counterevidence if prejudices were universal generalizations. But if prejudices really are stereotypes, they will turn out to be rather more epistemically robust than this simple picture would suggest. For the evidence that he now acquires can be shown to be quite compatible with his prejudice - in fact, on plausible assumptions, it is even predicted by it. The reason is simple enough: the intelligent women that Solomon encounters at the university do not represent a random sample of the female population. Instead, they are a skewed sample, largely selected for the trait in question, namely intelligence.

Let us attempt to tally, in a rough and ready way, the evidence available to Solomon after he enters the University. There is, first, robust testimonial evidence from his upbringing that women are less intelligent than men. Second, there is empirical evidence from his interaction with women in his community which appears to confirm the testimonial evidence. Finally, there are the several positive instances of female intelligence encountered at the University. Does this last batch of evidence require him to reassess his prejudice against women? We can imagine Solomon reasoning as follows: while women are on average less intelligent than men, some women are more intelligent than others, and some are indeed so intelligent as to be the functional peers of all but the most brilliant men. Where might one hope to meet some of these women? At the university, of course! Thus, the current evidence is in fact predicted by his prejudice along with plausible background assumptions. As such, if he were entitled to his negative stereotype prior the entering the University, there is no clear reason why he should be required to revise it subsequently. Contrary to the common view, it is not the case that Solomon's previously 
acquired evidence is nullified as he encounters instances of intelligent women. Instead, it remains active, and reasonably controls his interpretation of the new evidence acquired. (The evidence that he acquires does, of course, require him to treat these women with due recognition of their intelligence. Psychological research on implicit bias has done much to document the fact that prejudiced people often fail to extend precisely such recognition. ${ }^{4}$ Important as this issue is, however, we would do well to keep it distinct from the more narrowly epistemic question at stake here. For one can treat intelligent women with due recognition yet remain prejudiced.)

5. It might be objected that this argument underestimates just how negative a view Solomon takes of female intelligence. But this will not help salvage the connection between prejudice and epistemic culpability. To see why, let us assume that Solomon took an extremely dim view of female intelligence, such that there was little or no overlap between the curves. Of course, now his new evidence would clearly require him to reassess his stereotype. Yet the fact remains that he can do this while retaining his belief that women are on average less intelligent than men. What the new evidence requires him to recognize is simply that the discrepancy is less pronounced than he previously believed. Thus, importantly, the resulting revised view is still prejudiced against women (albeit less prejudiced than previously). But Solomon is evidently epistemically blameless in holding it: he has responded correctly to the new evidence that he acquires. And so, the common view has failed to establish a strict connection between prejudice and epistemic culpability.

\footnotetext{
${ }^{4}$ Greenwald and Banaji 1995. For an important application of this research to the situation of women in academic philosophy, see Saul 2013.
} 
A more probing objection would point out that my argument so far has worked with a rather narrow conception of epistemic blamelessness: one is epistemically blameless if one has assessed one's actual evidence in a reasonable fashion. Might there be some broader sense in which someone like Solomon could be said to be epistemically culpable? To be sure: Solomon's actual evidence is but a small subset of the potential evidence available to him. It is natural to take on a normative tone of voice here: Solomon's interest should in some sense be piqued when he encounters intelligent women; he should in a sense seek more evidence, for instance by seeking to encounter women from a broader range of the population. And if he were to seek out that evidence, he might be rationally required to reassess his stereotype. Although neither Arpaly nor Fricker seem inclined to take this route, Solomon might, then, be culpable for failing to pursue evidence when the opportunity is there.

I do not think this line of reasoning is entirely without warrant. But note that this would constitute epistemic culpability by omission rather than commission. And here, there is a real danger here that we may end up holding Solomon and his ilk to higher epistemic standards simply because their stereotypes are false. While we may allow that the line between omission and commission is sometimes hard to draw, this is not a notion of epistemic culpability sufficiently robust to ground the sort of view that Arpaly and Fricker aim for. We are all, even the straight thinkers among us, epistemically culpable (by degrees) in this sense. For us, as for Solomon, there is a vast mass of available evidence that we simply neglect to seek out.

Take, for instance, Fricker's example of the honest used car salesman (2007: 42). Some contextualization may be necessary: Fricker's account involves a general endorsement of the role of what she calls "credibility heuristics" in testimonial exchange. Reliable stereotypes, even negative ones, constitute a "proper part of the hearer's rational resources in the making of 
credibility judgments" (2007: 30). Without the aid of such judgments, the hearer "will not be able to achieve the normal spontaneity of credibility judgments that is characteristic of everyday testimonial exchange" (ibid: 32$)^{5}$

The example of the used car salesman is intended to illustrate the fact that even reliable stereotypes might occasionally be misleading. Thus, I might encounter one of the few honest car salesmen around and give him a low credibility rating based on the stereotype that used car salesmen are dishonest. Although I have misjudged the particular car salesman in question, I am not epistemically culpable (given that the negative stereotype of used car salesmen is a generally reliable one, according to Fricker). Instead, I have suffered a bit of epistemic bad luck. Accordingly, I have not displayed prejudice against him, and he cannot claim to be wronged by my stereotype, in the sense of wronging that constitutes an epistemic injustice.

Personally, I would not presume to know to by experience whether used car salesmen are generally dishonest, so I cannot speak to the reliability of the stereotype in question (though I do, of course, have ample testimonial evidence to this effect). The negative stereotype against used car salesmen in our culture is largely maintained on anecdotal evidence whose source and veracity few of us would bother to check. Yet we believe ourselves entitled to hold that stereotype. Here, I argue, we omit to seek counterevidence to our negative stereotypes no less than Solomon. We all rely on stereotypes in handling our everyday epistemic transactions. There is, as Fricker affirms, nothing wrong with this. It may well be that our stereotype is true while Solomon's is false. But our question concerns the epistemology of prejudice. And it would be

\footnotetext{
${ }^{5}$ We can thus see Fricker's argument as an application specifically to the problem of testimony of more general social-psychological ideas about the cognitive utility of categorization and stereotyping in coping with a complex environment. For an overview of this literature, see Gendler 2011: 38-41.
} 
disingenuous of us to hold Solomon culpable for his beliefs simply because they are false: considered in its own right, his epistemic practice is scarcely worse than ours.

I conclude that a notion of epistemic culpability by omission rather than commission is not robust enough to distinguish Solomon's negative stereotypes from the ones that we believe ourselves entitled to rely on in our everyday affairs. If Solomon is prejudiced - as I believe he is - it is not obvious that he need be epistemically culpable for it.

6. As we have seen, the common view portrays the epistemology of prejudice in a rather naïve light, as involving simple mistakes in updating one's beliefs in the light of new evidence. By contrast, I believe that any attempt to understand prejudice - whether from a detached philosophical perspective or as one engages in critical assessment of one's own cognitive outlook - must proceed from a recognition of the extent to which prejudice is epistemically insidious. In this final section, I will briefly sketch an account of the character and source of this property of insidiousness.

It is by now a familiar insight from confirmation theory that people with different background beliefs ("theories") may reasonably differ in their assessment of the significance of new evidence. ${ }^{6}$ The point can be conveniently stated in terms of Bayesian theory, although it by no means depends on it: the significance of new evidence to existing beliefs ("hypotheses") depends on the prior probabilities that one assigns to the evidence and to the hypothesis under consideration. As we have seen, Solomon might assign a very low prior probability to the hypothesis that women are as intelligent as men at the same time as he assigns a relatively high

\footnotetext{
${ }^{6}$ See Kelly 2007 for an overview of the role of background belief in the assessment of evidence.
} 
prior probability to finding evidence of female intelligence in a university setting. In light of these prior probabilities, his encounters with intelligent university women demand little if any adjustment to his background beliefs. But with different background beliefs, the significance of the evidence might be very different.

These observations should clearly move us to ask how anyone could be epistemically entitled to hold such negatively charged background beliefs in the first place. But as we saw in section 2, both Arpaly and Fricker agree that Solomon's theory receives strong support from multiple evidential sources at the time in question. If this is correct, then Solomon is not only excused for harboring negative stereotypes against women; there may even be a sense in which he would be at fault for failing to harbor them.

It is worth homing in on one such source of evidence in particular, namely testimonial evidence that is filtered through socialization and early childhood education. Such evidence is crucial in providing us with an initial epistemic orientation in the world. ${ }^{7}$ But it also the source of many of our social stereotypes. In cases where the stereotypes are reliable, this is presumably beneficial: ${ }^{8}$ the evidence is vast and complex, and the testimonial stereotypes represent the accumulated wisdom of an epistemic community spanning generations. In cases where the testimonial beliefs are false, by contrast, it is clearly pernicious. Nonetheless, from an epistemological point of view, the cases appear symmetric. Testimony is evidence even when it is false or misleading; unless we are in a position to meet the testimony with contrary evidence or to discredit its source outright, we are rationally required to adjust our beliefs in accordance.

\footnotetext{
${ }^{7}$ See Harris 2012 for an account of the role of testimony in children's cognitive development.

${ }^{8}$ See, e.g., Fricker 2007: 30-32.
} 
Given the role of testimonial evidence in children's overall cognitive economy, I assume that we cannot as a general rule hold individual children culpable for acquiring testimony-based prejudices in the first place. But once prejudices are internalized as background beliefs, they quite reasonably come to perform a controlling function with respect to the interpretation of subsequent evidence, as we saw above. Consequently, they are extremely hard to dislodge. And so it is that one can rationally maintain one's prejudices even in the face of data that others with contrary background beliefs - would take to be strong evidence against. Accordingly, prejudiced people are not simply contradicting themselves when they accept that there exist intelligent women, peaceful Muslims, or Norwegians with a sense of humor.

To see how prejudices are capable of absorbing or subsuming such contrary evidence, we must recognize that they paint a more complex picture of the world than the common view assumes. This is the insight that we gain from the realization that the logical form of prejudices is better captured in terms of generics than in terms of universal generalizations. ${ }^{9}$ If prejudices took the form of universal generalizations, they would be epistemically fragile; easy to diagnose and dismiss, even from a first-person perspective. By taking this position, the common view unwittingly encourages the idea that we can know, simply by making sure we are correctly applying the canons of inductive inference, that our social cognition is free of prejudice. I believe this idea is misguided and pernicious: instead, it belongs precisely to the insidiousness of prejudice that they are epistemically robust, in the sense of being highly recalcitrant to apparent counterevidence and therefore often invisible to introspective reflection.

\footnotetext{
${ }^{9}$ See Rhodes et al. 2012 for recent work exploring the role of generic language in disseminating and sustaining social stereotyping from early childhood.
} 
None of this is to deny that many instances of prejudice are (also) held in place by the irrational contrivances of bias, motivated believing, or similar mechanisms. It is, rather, to deny that they must always or necessarily involve some such distinctive and specifiable manner of epistemic culpability. Though comforting, the common view of the epistemology of prejudice is false: many prejudices belong on a scale with the social stereotypes that we all invest our trust in on an everyday basis, often without even recognizing them as such. Since Fricker herself brings the notion of epistemic luck to the table, it is tempting to deploy it in drawing a contrary conclusion: what distinguishes us from Solomon and his ilk may largely be a matter of our good epistemic luck, i.e., the luck of being bequeathed from early age with social stereotypes that are largely true (or so, at least, we like to believe).

\section{Acknowledgments:}

Discussions with Holly Andersen have led to improvements at virtually every point in this paper. Thanks also to students in my Spring 2013 undergraduate philosophy course at Simon Fraser University, where I first broached these ideas.

\section{References:}

Arpaly, Nomy. 2003. Unprincipled Virtue: An Inquiry into Moral Agency. Oxford University Press.

Fricker. Miranda. 2007. Epistemic Injustice: Power and the Ethics of Knowing. Oxford University Press. 
Gendler, Tamar Szabó. 2011. "On the Epistemic Costs of Implicit Bias.” Philosophical Studies 156(1): 33-63.

Greenwald, Anthony G., and Mahzarin R. Banaji. 1995. "Implicit Social Cognition: Attitudes, Self-Esteem, and Stereotypes.” Psychological Review 102(1): 4-27.

Harris, Paul L. 2012. Trusting What You're Told: How Children Learn from Others. Cambridge, MA: Belknap Press.

Kelly, Thomas. 2008. "Evidence.” The Stanford Encyclopedia of Philosophy (Fall 2008 Edition), Edward N. Zalta, ed., URL = <http://plato.stanford.edu/archives/fall2008/entries/evidence/ $>$.

Leslie, Sarah-Jane. 2008. “Generics: Acquisition and Cognition.” Philosophical Review 117(1): $1-47$.

Leslie, Sarah-Jane. Forthcoming. "The Original Sin of Cognition: Fear, Prejudice, and Generalization.” To appear in Journal of Philosophy.

Rhodes, Marjorie, Sarah-Jane Leslie, and Christina M. Tworek. 2012. “The Cultural Transmission of Social Essentialism." Proceedings of the National Academy of Sciences (PNAS) 109(34): 13526-13531.

Saul, Jennifer. 2013. "Implicit Bias, Stereotype Threat, and Women in Philosophy." In Katrina Hutchison and Fiona Jenkins, eds., Women in Philosophy: What Needs to Change? Oxford University Press. 